\title{
Restorative Counter-Spacing for Academic Sustainability
}

Published in : Jones, D. (2014) Restorative Counter-Spacing for Academic Sustainability, Organization \& Environment 2014, Vol. 27(3) 297-314.

David R Jones: Associate Professor in Strategy

Bournemouth University

BH19 2EN

Email: drjones@bournemouth.ac.uk

Tel No. 01202-62702

\section{Abstract}

By combining pertinent theories from environmental psychology and human geography, this paper proposes a socio-spatial framework of principles, which could be used by academic actors, to reflexively embody and critically enact a bio-cultural connection. It contributes to an emerging line of research, which explores the importance of deepening attachments to local natural settings. By reflecting on an auto-ethnographic, personal account of a "Whale Watching” experience and indicative international university initiatives such as the "Oberlin Project”, in the U.S.A., and the "University in a Garden”, in Malaysia, the paper will test out these principles as both an institutional and individual signpost for academic sustainability.

Key Words: Sustainability, Academics, Heterotopias, Space, Attention Restorative Theory.

\section{Introduction}

This paper concurs with Cortese (2003), who argues that higher education has unique potential to catalyze and/or accelerate a societal transition towards ecological sustainability. However, Lozano, Lukman, Huisingh \& Zilahy (2010) recognize that many university and college actors, such as staff, students and local community groups, are struggling to meaningfully contribute to sustainability. More specifically, Jones 
(2012) highlights, many academics are feeling cynical, powerless and mistrustful of the ecological sustainability agenda of their universities and are emotionally disconnected from the diverse ways of viewing and enacting the biophysical environment (Macnaughten \& Urry, 1998). This paper thereby follows the call from Collins and Gannon (2014) who highlight that faculty researchers look reflexively at their own profession's and positions' sustainability profiles and identify how they might individually and collectively exert more of a sustainability impact on their respective stakeholders and societies. It also follows Sharma and Hart's (2014) advice for researchers to look beyond their traditional disciplinary boundaries, to identify a wide range of theories that could highlight how sustainability management academics can most effectively contribute to higher educational leadership (Starik \& Turcotte, 2014).

Whilst researchers such as Disterheft, Caeiro, Ramos \& Azeiteiro (2012) recognise certain performative, operational benefits of popular campus initiatives, such as around environmental management systems approaches, an emerging group of researchers highlight that many academic actors view their universities as fundamentally contributing to the sustainability crisis through campus and curricular "greenwashing” (Huisingh \& Mebratu, 2000; Mochizuki \& Fadeeva, 2008; Sanusi \& Khelgat-Doost, 2008). From a business school curricular perspective, Sharma and Hart (2014) highlight that virtually all sustainability curriculum initiatives, centres, or institutes continue to merely hang off the side of the existing business school institutional edifice. They compare this to the proverbial "saddle bag" on a horse, where sustainability issues are contained within separate compartments that are readily visible from the outside but have little impact on 
the behaviour of the animal itself. Whilst they recognize that some independent and pioneer institutions are co-creating integrated sustainable MBA programs with faculty and practitioners, they also recognize that such initiatives have minimal impact institutionally. As Huisingh \& Mebratu (2000) argue, the institutional environment of academia is still reproducing a paradigm, which underpins the controlling, exploitative relationships of people with the biophysical environment.

Kearins, Collins \& Tregidga (2010) argue that the particular form of controlling relationship manifests itself through a managed, goal directed, modernist narrative of nature. This narrative does not reveal the contested, materially and socially-constructed, multiple meanings of nature, which could potentially shift or re-enchant the various university actors’ relationship with nature. Macnaghten and Urry (1998) similarly highlight that this represents the abstraction of singularity from the multiple meanings, ambiguity and complexity of nature. Such diversity ranges from nature as landscape, as an object of scientific scrutiny, as threatened and in need of protection, as a resourceproviding system, or as a source of spiritual renewal (Macnaghten and Urry, 1998). Moreover, in their preoccupation with the externalities of the "triple bottom line" of sustainability agendas and latterly, with the tangibles of standardization and measurement, universities have veered further away from engaging with what McIntosh (2004) describes as the inscape/landscape dialectic. This describes the intangible "soil and soul” dynamics that bring a sense of completeness and grounded identity from being at one with the living Earth. 
In light of the above institutional performative pressures, this paper aims to explore how academics might embrace the wider, multiple meanings of nature in order to build a greater bio-cultural connection. Following Ryan’s (2011) spatial educational focus, the author argues this can be done through the process of counter-spacing, focusing on surprising, reflexive, contesting, embodied spaces.

The particular form of academic counter-spacing proposed here draws on Attention Restorative Theory (ART) (Kaplan \& Kaplan, 1989), from the environmental psychology discipline, as its conceptual inspiration. Drawing from ART, the proposed restorative counter-spacing in universities explicitly responds to Morgan's (2011, p.474) challenge of finding images and ideas, that will have real power in constraining or reversing the overassertive relationship between organisations over their context, with particular attention to the bio-physical environment.

In order to aid the socio-spatial enactment of restorative counter-spacing, Foucault's (1984) concept of "heterotopia" is used here. Such a concept represents a means to point to different, other spaces that contest the space we live in, whilst providing a context for action (Steyaert, 2006). Moreover, the paper follows the work of Beyes \& Michels (2011) around how a university could develop a generative, process-based, potential heterotopic "other" space. They focus on the example of an experimental, alternative teaching project for 850 newly enrolled students, from across a European business school, who were asked to conceive of and visualize a city of the future, called "FuturoPolis", within five days. They were supported by 150 multi-disciplinary tutors, visiting artists and 
architects. The emergence of "other" spaces, such as around performance art installations, that were not necessarily planned or conceived, facilitated a critically affirmative student engagement with the business school. As the authors report, "we were both surprised and moved by what presented itself to us as a space of possibility and potential, full of simultaneous heterogeneity, an 'affective space of unanticipated encounter and connection' (Rajchman, 1998, p. 91) in an atmosphere in which the boundaries between possible and impossible, between real and imagined were temporarily disturbed" (Beyes \& Michels, 2011, p. 533).

The reflexive enactment of the notion of heterotopic restorative counter-spacing represents a direct contrast with utopian metaphors, such as "nature as island" (Philipon, 2004; Keulartz, 2007). The implication of such a heterotopic, socio-spatial enactment is that it moves beyond deterministic, managerial attempts at incremental quick fix prescriptions. Such incremental prescriptions would be around discreet, naturalistic experiences, contemplative spaces or deterministic design parameters for a particular discipline, such as biophilic design in architecture (Kellert, 2008). Furthermore, recalling the arguments against utility and performative consequences of education (Dey and Steyaert, 2007), this paper's focus is not to introduce a new sustainability strategy or set of performance measures and targets. In contrast, it represents a new possible experiment in identifying pertinent bio-cultural counter-spacing pathways. The following sections will initially justify the spatial focus of the paper. It will then justify the use of ART and explore centrally how the different principles of ART combine with the different 
heterotopic principles, to conceptually point towards potential bio-cultural pathways for academics.

\section{Spatially Framing the Research Question}

Kellert (2008) argues that a bio-connection is enhanced through a process of developing a sense of ecological place and responsibility. Gould (2000, p.12) argues that if discourses of sustainability are to retain their radical and political edge, they "must ultimately be rooted in the relationship between specific human populations and specific ecosystems located in specific places”. People are rarely sufficiently motivated to act as responsible stewards of the built environment, unless they have a strong attachment to the culture and ecology of place (Kellert, 2008). As Wendell Berry (1972, p.68) remarked: "Without a complex knowledge of one's place and without the faithfulness to one's place on which such knowledge depends, it is inevitable that the place will be used carelessly and eventually destroyed.” For example, Whiteman and Cooper (2000, 2006) and Whiteman (2004) have cogently explored the implications of ecological embeddedness among indigenous communities. They argued that personal identification with one's physical

place, adherence to ecological beliefs, gathering of firsthand ecological information, and physical location in the ecosystem will promote more commitment to sustainability than the modernist dislocation of individual, community, and ecology. Similarly, Johnson (2012) and Walck $(2003,2004)$ have explored the significance of deepening attachments to local natural settings. This paper thereby follows this research and concurs with Shrivastava \& Kennelly (2013), who advocate that sustainability can better be understood 
by examining the complexities and multiple meanings around rootedness in place. More specifically, it follows research which examines organizations as "place builders" (Thomas \& Cross, 2007) with the recognition that place encompasses not only the natural and man-made environments but also the cultural and social dimensions that give places meaning (Guthey \& Whiteman, 2009).

In the context of this wider meaning-making perspective, this paper centrally focuses on socio- spatial perspective of universities. It follows Tuan (1977) who argues that place emerges out of space, and that the two concepts require each other for definition. To Tuan, places are stable and secure; whereas spaces are open, free and more threatening, and "if we think of space as that which allows movement, then place is pause; each pause in movement makes it possible for location to be transformed into place” (Tuan, 1977, p. 6).

Moreover, as Beyes and Steyaert (2012, p.53) argue, being attentive to the open-ended and processual notion of "spacing", rather than "space” is pertinent here. Spacing orientates the understanding of organizational space towards its embodied, affective and minor configurations. Spacing directs the organizational scholar towards encounters, generated in the here-and-now. It thereby explicitly recognizes that actors conceive, appropriate and socially produce their own lived, experienced and embodied spaces. Therefore, at best this paper is an attempt to offer a potential opportunity for spacing, which could possibly be embodied and experienced in diverse bio-cultural terms. 
More specifically, following Beyes \& Michels (2011), at an institutional level, it is guided by the question of how universities can open up opportunities for "counter spacing” or “other spacing”, which could respectively open up to positive, emancipatory power for its various academic actors. Surprising things could happen in these "other spaces”. A pertinent example is the architectural notion of the generative building, where surprises are embraced as a form of positive power that cannot be intentionally produced and controlled by the designated "architect” from the top-down. Moreover, generative buildings are what Rudofsky (1964) has called “architecture without architects”, a “nonpedigreed architecture”, planned anonymously, emerging spontaneously, changing unpredictably, shaped by the creativity of the users and developed just-in-time (De Certeau 1984). It is clearly not driven by the functionalist belief that form follows function. Accordingly, this paper is inspired by Kornberger \& Clegg (2004), who pose the rhetorical question of whether functions evolve from spatial forms. This paper follows this logic, exploring which counter spatial form could offer academic actors the emergent bio-cultural spacing function, to initially disrupt the usual horizons of time and space within universities. Furthermore, which spatial form could latterly contest the dominant singular views of nature, by opening up a discourse, which recognizes and produces a diverse bio-cultural connection with nature?

\section{Conceptual Underpinning: Attention Restorative Theory \& Heterotopic Spacing}

In searching for a pertinent counter spatial form, this paper specifically draws on Attention Restorative Theory (ART), derived from environmental psychology. It thus draws on the intent of Taylor and Spicer (2007, p. 326) who point out that, while "the 
field of organizational spaces is approaching maturity”, stronger links need to be made 'between this emerging field and other social science analyses notionally 'outside' the field of business management”.

The specific rationale behind the choice of ART is based on the importance of a context in which an involuntary or non-directed, absorbed attention is effortlessly engaged, intrigued and captured without mental fatigue (Herzog, Black, Fountaine \& Knotts, 1997). ART offers a theoretical basis for restoring the human relationship with the biophysical environment. It achieves this by identifying the underlying spatial form and related attributes shared by specific natural environment- person interactions, which foster not only psychological and physical restoration, but bio-cultural restoration as well (Hartig, Bringslimark \& Gridal Patil, 2008). More significantly, this paper draws on research around natural environment settings, exhibiting ART factors or attributes. For example, Hartig, Kaiser \& Strumse (2007) highlighted that these settings not only restored directed attention, reduced stress, improved physical and emotional well-being and reflection, but also increased pro-environmental behavior. In the context of this paper, the question moves beyond the natural environment and setting towards how such underlying natural environment-person interactions could be translated into a university socio-spatial context. Whilst studies have consistently demonstrated that natural environments are more restorative than urban or built environments, Ouellette, Kaplan \& Kaplan (2005) highlight that there appears to be a paucity of research around academic settings. The paper's contextual focus on universities follows other ART research around museums, favorite places and monasteries (Kaplan, Bardwell \& Slakter, 1993; Korpela, 
Hartig, Kaiser \& Fuhrer, 2001; Oullette et al, 2005), in fostering a spatial sensibility around a critical, bio-cultural engagement.

The core of the paper will endeavor to explore the role of ART's four principles or attributes (defined in later sections) within the socio-spatial enactment of restorative counter-spacing (Kaplan \& Kaplan, 1989):
i) “Being-Away",
ii) “Fascination”,
iii) “Extent” and
iv) “Compatibility”

As prior research around these four ART principles has only explored their broad physical or spatial qualities (Herzog, Maguire \& Nebel, 2003), this paper endeavours to develop a conceptual clarity around such an emergent enactment. It aims to explore how the principles may be expressed in socio-spatial form, particularly with respect to a university context. Therefore, the following section endeavors to gain a social-spatial understanding of restorative counter-spacing, through connecting the different ART principles with Foucault's (1984) heterotopic principles. These six heterotopic principles (elaborated in later sections) are as follows:
a) heterotopias have systems of opening and closing;
b) heterotopias function in relation to all remaining space;
c) heterotopias are linked to "slices of time";
d) several spaces may be juxtaposed in a single heterotopia;
e) the function of a heterotopia may change over time; 
f) heterotopias may be either based on crises or deviance.

This integrative, interdisciplinary search for compatible socio-spatial principles also aligns with the work by Sloterdijk (2010), in the call for education to embrace the imaginative geographies of spatial production (Lefebvre, 1991).

In line with the experimental tone of visualizing such restorative, heterotopic, counterspacing, an associated personal vignette will initially be reflected upon for each of the ART principles. This vignette is around an on-going search for restorative spacing within academic sustainability conferences. It is an analogous representation of the challenge and potential of enacting a restorative, heterotopic space in revitalizing interest and action in the context of ecological sustainability. The paper will then explore potential internal and external, campus counter-spacing initiatives: the "University in a Garden”, in Malaysia and the “Oberlin Project”, in the U.S.A., in relation to the proposed ART/heterotopic framework.

\section{Enacting Heterotopic Spatialities of Restorative Spacing}

Being-Away implies a setting that is physically or conceptually different from one’s everyday environment.... situations that involve psychological distance from aspects of one’s usual routines (Kaplan \& Kaplan, 1989).

With respect to such a definition, one would expect academic spacing to be a good candidate for potential restorative experiences, as universities are potentially distinct and sufficiently apart from one’s everyday settings, both physically and psychologically 
(Ouellette et al., 2005). However, as argued previously, many universities are far from restorative as they are propelled by an institutional environment, which promotes a dominant instrumental sustainability discourse. The campus discourse focuses on carbon management prescriptions, management systems, audits and conformance to published league tables/institutional rankings (Stibbe 2009). From a business school perspective, sustainability management academics working within such institutional environments are also constrained at the curricular and research level, by their disciplinary and functional academic training and career progression, towards the pursuit of tenure and promotion (Sharma \& Hart, 2014). Furthermore, the associated legitimising incentive at the senior decanal level of being seen to efficiently and continuously manage institutional ranking position, year on year, and be signatories to various sustainability declarations, such as Principles for Responsible Management Education (PRME), often masks a wider biocultural disconnection in universities (Jones, 2012). Sharma and Hart (2014) also highlight that whilst most leading business schools have become signatories of PRME since the late 2000s, it has had a very limited impact in motivating, or helping business schools, to integrate sustainability into their core curriculum.

In the context of enacting the principle of Being Away, the emerging question becomes how could academic actors reflect on and potentially contest such institutional pressures. In this context, the purpose of enacting the Being Away principle could be construed as not to solely temporarily escape, but also to challenge such dominant practices. In order to enact such a heuristic notion, it is argued here that Foucault's (1984) heterotopia could prove appropriate. The term heterotopia originally comes from anatomy, where it is used 
to refer to parts of the body that are out of place, missing, extra, or like a tumor, alien. As Steyaert (2006) argues, the dual role of a heterotopia is both as a reflective space and a context for action to potentially contest the space we live in. Heterotopias, "have the curious property of being in relation with all the other sites, but in such a way as to suspect, neutralize, or invert the set of relations that they happen to designate, mirror or reflect” (Foucault,1997, p. 265). A heterotopia, “exerts a sort of counteraction on the position that I occupy” (Foucault, 1997, p.266). This potential contested relationship to the instrumental aspect of universities, relates to one of the heterotopic principles, which points at a system of opening and closing that both isolates heterotopias and makes them accessible in a special way.

For example, a heterotopia of illusion is where space and time could be collaged at will (in museum period rooms or on stage or, of course, potentially within a university) and codes of behavior could change very rapidly. A heterotopia of illusion creates “a space of illusion that exposes every real space, all the sites inside of which human life is partitioned, as still more illusory. A heterotopia of illusion endeavors to expose what Bateson (1967, p.10) refers to as “our absorbed societal beliefs and constructs which foster our illusions of supremacy, dominance, separation from the 'natural' world and immunity from the consequences of our eco-systemic ignorance”. This reflects another heterotopic principle, which states that heteroptopias "have a function in relation to all the space that remains.” The principle of being-away, enacted through a heterotopia of illusion, thereby highlights how academic counter-spacing could be contextualized as a 
mirror, reflexive space, where a non-instrumental, contesting discourse could potentially emerge.

As an organizational studies academic in the sustainability field for 20 years, the author can certainly reflect upon the continual personal need to find a heterotopic, reflective, mirror space around the many conferences the author has attended i.e. to "Be-Away". Moreover, the author finds himself desperately searching for bio-cultural restorative times and spaces to counter a diminished personal engagement with these increasingly performative conferences arising from their embedded bio-cultural disconnection (despite their sustainability focus). Paradoxically, this is not a search for a break from the conference discourse but an implicit, reflexive recognition regarding the ART hypothesis, that the search for a heterotopic space, fostering in-directed attention, would ultimately engender a more creative, reflective directed attention and potential challenge towards such sustainability discourse. One such personal experience stands above all others for the author, a memorable "Whale Watching” trip in Nova Scotia, which emerged as a reflective, playful space of potentiality, exposing for an eclectic group of academics, the illusory nature of the main sustainability conference. The narrative thread of this vignette will be elaborated upon within the following sections, in order to illustrate the potential socio-spatial enactment of each of the various ART principles.

Fascination is an involuntary or non-directed, absorbed attention, in which an individual's attention is effortlessly engaged, intrigued and captured without mental fatigue. Our attention is aesthetically engaged, although no response from us is required (Kaplan \& Kaplan, 1989). 
Apart from the numerous restorative benefits discussed previously, this non-directed attention was originally shown to be critical in restoring the mental fatigue of our overused directed attention (Kaplan \& Kaplan, 1989). This engagement varies in intensity along what Kaplan (1995) refers to as, a "soft-hard" dimension. It is argued that Soft Fascination, which is moderate in intensity and generally focused on aesthetically pleasing stimuli, common in natural settings, permits an opportunity for attention restoration. Watching clouds, the motion of leaves, or the play of light are examples of Soft Fascination (Kaplan \& Kaplan, 1989). Research indicates that being in a natural setting, or viewing natural settings can effectively induce non-directed attention. In contrast, Hard Fascination rivets one’s attention and generally does not allow for attention restoration. Both overload and arousal theories argue that human perceptual systems can become overloaded and stressed in places that have a great deal of complexity or intensity, in visual terms or through noise and movement. Both theories imply that restoration from stress or perceptual fatigue should be fostered by settings having stimuli, such as plants, that are low in intensity and incongruity.... That reduces arousal and processing effort (Ulrich \& Parsons, 1992).

Similarly, Hancock (2003) argues, the danger of an over-stimulation of the aesthetic numbs our facilities of experience and judgement. Welsch (1997, p. 25) recognizes that, “our perception needs not only invigoration and stimulation, but delays, quiet areas and interruptions too... Total aesthetization results in its own opposite. Where everything becomes beautiful, nothing is beautiful any more; continued excitement leads to 
indifference; aesthetization breaks into anaesthetization.” This paper endeavors to avoid total aesthetization and the associated anaethetization, by moving beyond such calls for “delay and quiet”, and conceptualizing the Soft Fascination aesthetic. In other words, it focuses on a particular "aesthetic as [bio-cultural] connection”, as described by Taylor and Hansen (2005). This concurs with how a selective, low intensity, reductive palette of nature is absorbing or fascinating to the eye (Krinke, 2005). In other words, the focus on restoring the connection with the biophysical environment, represents a space, where the primacy of the embodied tacit aesthetic/sensory knowledge, (Polanyi, 1958) around this bio-cultural connection, offers fresh insight, awareness and enables us to see in a new way (John, 2001).

Aesthetics for the sake of aesthetics (rather than in the service of instrumental goals) may be hugely important in the long run, particularly with respect to restoring our so-called innate bio-cultural connection (Ulrich. 1993). The primary focus on the aesthetic/experiential, rather than the instrumental, within restorative counter-spacing does not mean that the rationale, cognitive forms of knowing are neglected, merely slowed down i.e. in the cognitive sense. Moreover, it reflects that this experiential or aesthetic knowing is not only a separate way of knowing, but that other forms such as those derived from rational thought depend on, and grow out of aesthetic experiences (Gagliardi, 1996). This is at the core of ART, as it asserts the importance of non-directed attention in the restoring of directed attention. In other words, aesthetic experiences are constantly spilling over and being integrated into other activities, enhancing and deepening them (Shusterman, 2001). Similarly, Dey and Steyaert (2007) argue that such 
a focus has the potential to expand the process of knowing beyond its cognitive limits to all senses, reintroducing "the body, the emotions, the affective mode of understanding, intuition, receptiveness, empathy, introspection and aesthetic understanding” (Gherardi, 1999, p 110). This corresponds to findings in the transformative learning literature, where there appears to be a broadening of perspectives on learning from that which is strictly a cognitive process, to a more inclusive, integrative, holistic, or integral perspective. Cranton and Roy (2003, p. 90) state that "the central process of transformative learning may be rational, affective, extra-rational, experiential, or any combination of these depending on the characteristics of the individual and the context in which the transformation takes place”. These holistic ways of knowing are gradually being recognized in adult and higher education. A study by Duerr, Zajonc, and Dana (2003) documents universities in North America which incorporate intuitive, imaginative, spiritual, and contemplative dimensions of education.

Returning to the personal analogous "Whale Watching” vignette, the underlying motive for restorative spacing typifies the personal need to reflect on and contest the cognitive, political and instrumental walls of the academic sustainability conferences, which the author has attended. The "Whale Watching” trip aided the author's understanding of the value of the aesthetic experience over the cognitive and yet at the same time informed the cognitive. Our guide for the day was a well-informed and inspirational speaker, who provided a kaleidoscope of information about the whales in question and we were happy, at least for the first hour or so, to let this more than able "academic" satisfy our intellectual expectations. This was no mean feat as we were a diverse_set of academics 
from many different fields. However, our reaction to this individual dramatically changed, when we were fortunate enough to spot and then be within a few meters from a pod of whales..... as a tail fin rose out of the water our guide quickened his cognitive pace and began to elaborate on the social and environmental predicament of these animals. This became such an annoying distraction, that almost in unison several of the party politely, but abruptly asked the guide to be silent. It was only then that many in the party developed an absorbed, soft-fascinated, non-directed experience, which was memorable enough to inspire many of us to engage on a more embodied level with the guide. The cognitive silence or slowness enabled time to appear to stand still for the audience, which represented both an intensely personal and collective, affective event, concurring with another heterotopic principle around special slices of time. Elaborating on this Foucault (1997, p. 272) argues, "heterotopias are as much special spaces as special slices of time, so-called heterochronies, times where people break radically with their traditional time, such as when you enter a cemetery, where time can stand still, or when you enter a library or museum that tries to enclose in one place all times, all forms, an immobile place that is itself outside of time.

The following ART principles reflect on the personal and professional consequences for the group of academics and guide who shared this enacted timeless form of Fascination.

Extent is the quality of a physical or conceptual setting sufficiently rich and coherent that it can engage the mind and promote exploration (Kaplan \& Kaplan, 1989).

An endless stream of stimuli both fascinating and different from the usual would not qualify as a restorative setting for two reasons. Firstly, lacking Extent, it does not qualify 
as a restorative, but merely an unrelated collection of impressions and secondly, a restorative space represents sufficient scope to engage the mind. It provides enough to see, experience, and think about so that it takes up a substantial cognitive processing of the mind (Kaplan \& Kaplan, 1989). These two aspects to Extent have prompted some authors to expand the number of components, by subdividing into Coherence (or Connectedness) and Scope (Purcell, Peron, \& Berto, 2001).

The notion of heterotopia is revisited again in relation to conceptualizing Extent, in the context of restorative counter-spacing, through exploring one more of the six heterotopia principles. Conceptualizing the cognitive engagement potential through the connected, scope aspects of Extent, Foucault (1984, p.272) argues, a heterotopia, "is capable of juxtaposing in a single real space several spaces, several sites that are in themselves incompatible”. With respect to this paper, academic restorative counter-spacing, which embodies the principle of Extent, would be able to connect the above transitory experiences and the associated disorientation of space, and thereby offer the potential for more enduring experiences inside and outside the university.

ART researchers have begun to focus their attention on people in their everyday contexts, such as in the residential and workplace setting, where they could ordinarily and regularly find possibilities for restoration over an extended period (Kuo and Sullivan, 2001; Kuo 2001; Kaplan, 2001; Wells \& Evans, 2003). Furthermore, universities have the possibility of acting as enduring potential restorative spaces, considering the length of time spent within universities for many actors. As Kaplan \& Kaplan (1989) point out, besides the 
spatial aspects of a restorative experience, the amount of time spent in these spaces is also a critical variable. Kaplan \& Kaplan (1989) have postulated that the restorative experience has four levels of development, each taking increasing amounts of time. The first level represents "clearing the head", the second is "the recovery of directed attention", the third is "the recovery of cognitive quiet" and the fourth level of a restorative experience represents "reflections on one’s life “, which may include "a concern for meaning, for tranquillity and for relatedness.” (Kaplan \& Kaplan, 1989, pp. 196-197). They note that this final level "is an aspect of the restorative experience we would never have suspected had it not emerged so clearly in our data.” (Kaplan \& Kaplan, 1989, p.197). Of course, in the context of this paper, such relatedness is not only with respect to the transpersonal but with the biophysical as well i.e. bio-cultural restoration.

Could a university offer the potential for such a relational experience through restorative spacing, focusing on developing bio-cultural meaning and significance? In other words, could a university offer the potential for paradigm-shifting, cumulative effects of multiple restorative experiences, rather than discreet, isolated, concrete, nature experiences within environmental education for example (Hartig, 2007)? Hartig et al (2008) highlight that an isolated experience will ordinarily do little to support adaptation in the long run. The discreet, temporarily bounded restorative experiences may have a cognitive, behavioral or emotional impact, but this impact may be short-lived. Furthermore, the spill-over effect into the day-to-day lived, embodied experience of organizational actors is negligible. A central concept in Dewey’s educational philosophy is the continuum of experience: “... 
the central problem of an education based on experience is to select the kind of present experiences that live fruitfully and creatively in subsequent experiences” (Dewey, 1938, pp. 25-28). Therefore, it conforms to John's (2001) argument that worthwhile aesthetic knowledge must be able to travel a bit beyond its acquisition site, allowing us to build upon that knowledge in other contexts. With its potential for long-term exposure, could a university socio-spatial context, such as that represented by the "University in a Garden" and the "Oberlin Project" (see later), offer the possibility of such a continuum of experience for academics?

In order to begin to answer such a question, the above personal analogous space vignette will again be reflected upon. The paper will explore the consequences around the potential experience spillover for the few academics privileged to have shared this whale watching experience. The eclectic group of individuals began to engage in multiple, collaborative, trans-disciplinary, sustainability discourse around enhancing the biocultural aesthetic, particularly embracing the humanities. This was represented by many stories around the lack of such aesthetic experiences within a university context. The artistic engagement fed into the whale watching experience itself and the didactic/discursive method of pedagogy of the guide duly changed, towards artful, participative constructions and productions to tap into the aesthetic sensibilities of the participants (Taylor and Hansen, 2005). Poetry, music, painting and drama_were all the results of such an aesthetic experience and have now transformed the nature of this whale watching experience or potential space for not only the creators and artists but for the future day-trippers in their own artful, participant construction of the whale watching 
experience. It is pertinent to point out that this form of aesthetic experience (Collinson, 1992) heightens the initial cognitive slow experience, described above, as it is actionoriented, where one is emotionally absorbed in the artistic task or activity rather than being passively absorbed in contemplation of an object or person. The experience develops the Soft Fascination aesthetic by engaging particular senses through the artistic form as chosen by the participant. This participant subjectivity will be reflected upon within the next section through the last of ART’s principles, Compatibility.

Compatibility, according to ART, is a quality of a setting that fits with and supports one's inclinations or purposes and the kinds of activities maintained, encouraged, or demanded by the setting (Kaplan \& Kaplan, 1989).

This subjective aspect of Compatibility is key to the definition of the other attributes as it describes them as "properties of a person-environment interaction, rather than of an environment per se.”(Kaplan \& Kaplan, 1989, p.482). For example, Kals, Schumacher \& Montada (1999) propose that whilst experiences with nature, dispose people to positive mood states and nature-protective behaviours, these effects are mediated or moderated by the extent to which this experience has meaning for the individual concerned. The design of an aesthetic experience needs to account for the subjective and contingent willingness to embrace the quality of the object (Gagliardi, 1999).

Heterotopic principles are again revisited in relation to conceptualizing Compatibility, in the context of restorative counter-spacing. Foucault (1984) argues that no single culture fails to constitute a heterotopia and emphasizes the contingent nature of a heterotopia. 
This fits the notion of restorative counter-spacing, as it represents an opportunity for all universities, to enact a heterotopia through different spatial forms, depending upon the institutional context. Such a space recognizes that a restorative space in one university context may be inappropriate in another (Hall 1959). The meaning of space varies with context (Flyvbjerg 2001). It is no surprise that Foucault was not very precise in his qualification of a heterotopia and he opted for a neologism. Although the above heterotopia principles have been critiqued as being unsystematically open (Soja, 1996), it allows a connection to be made between concept and reality for those universities, wishing to enact such a restorative space (Steyaert, 2006).

This leads to another heterotopic principle, which states that the same heterotopia can function in different ways, as it is played out in different settings or societies (Foucault, 1984). In the context of this paper, a university could act as a heterotopia and restorative experience for different reasons depending upon individual and collective subjectivity at a particular time, which can be viewed as the result of complex human-environment transactions. Therefore, ART's Compatible context here means not simply a preference for a physical setting or physical aspect of the environment (e.g. its natural or built features), but multiple, potential, global, restorative experiences (Korpela et al., 2001), contingent upon the physical, cognitive, emotional qualities of this human-environment interaction, within the restorative space at that time (Canter, 1977).

Therefore, this paper argues that only through the Compatibility notion of restorative spacing, different academic actors could possibly embody a "Restorative Experience". It 
is this Compatibility notion that is crucial in achieving change towards sustainability (Leach, 1998). As Lefebvre (1991, p. 59) argues, “Change life!” "Change society!” These precepts mean nothing without the production of an appropriate space. New social relationships call for a new space, and vice versa.

In terms of the earlier discussion around Being-Away, academics' restorative counterspacing can be enacted as varying from, not only illusionary, but crisis and deviant heterotopic experiences as well (representing the final heterotopic principle), depending upon the subjectivity of the academic actors involved. Such compatible spacing can be seen as surfacing the perception of an underlying "crisis" of bio-cultural disconnection (fitting within Foucault's notion of crisis in terms of crucial, but not always evident transitions in life and the body). It can also be seen as offering shelter and emotional, cognitive and aesthetic agency, whether temporary or permanent, to actors who then wish to deviate from such mainstream university norms and relationships, and potentially contribute to restoring a bio-cultural connection.

As a final reflection of the importance of the Compatibility principle within the personal vignette thread running through this paper, it is pertinent to note that the aforementioned whale watching experience actually took place back in 2003 and was completely separate from the main conference. The reflexivity and trans-disciplinary impact of such restorative, heterotopic spacing and the on-going bio-cultural experiences of academics, of local community and of business actors, have led to a generative discourse, which has spilled over into the lives of many of the original day-trippers. In fact, for many of the 
academics in particular, the initial experience has developed a radical change in the nature of their research and teaching career aspirations and philosophy, embracing emotional, temporal and aesthetic knowledge and bio-cultural sensibilities within their different sustainability fields.

Could academics and universities embrace such analogous spacing notions and vignettes? Moreover, rather than wait for spontaneous interaction outside of the hallowed halls of academia, could academics enact and embody restorative, heterotopic spacing to counter their universities’ current allegiance to more performative, institutional pressures. At the very least, could academics become more aware of the limitations and entrapment of such institutionalized pressures?

The next section will briefly outline various campus initiatives, which could potentially offer the opportunity for academic restorative counter-spacing. Within the concluding section, the paper will critically reflect on such initiatives, in the extent to which they could embody the various ART principles of the proposed framework.

\section{Potential Restorative Counter-Spacing Initiatives in Universities}

Possible internal counter-spacing initiatives, which move beyond incremental changes on campus (currently being researched by the author), include how the biophysical environment of the university campus itself could act as generative, ambiguous, heterotopic counter-space for the university as a whole. A pertinent example of such an initiative is the "University in a Garden” concept, as conceptualized by the Universiti 
Sans Malaysia (USM) in 2001-02. The Universiti Sans Malaysia has been recognized internationally by the Global University Network for Innovation (GUNI) for the University in a Garden initiative. As the university highlights (USM, 2012), the "University in a Garden” metaphor, “....is designed to depict the close affinity between the role and function of the University as an institution of higher learning, and nature as part of the global, ecological setting. The flora, fauna, aquatic elements and other natural creations are dynamically linked in the exploration of knowledge into the nature of existence. The concept is an invitation to value, preserve and nurture the campus ambience as part of the efforts to create and sustain an intellectually conducive setting, in order to kindle the spirit and practice of symbiotic co-existence. It is about touching the hearts and minds of each campus citizenry in the appreciation of the natural surroundings as a source of inspiration...." The university explicitly argues that the "University in a Garden" would allow it to deepen and translate its main mission as "a pioneering university, trans-disciplinary and research-intensive, that empowers future talents and enables the bottom billions to transform their socioeconomic well-being.” Furthermore it points out that this is in line with its vision of "Transforming Higher Education for a Sustainable Tomorrow.” The university also relates this mission and vision to reflection, "in the search for answers to further illuminate the questions of who we are, how we attained insights, and how we should fashion our future survival." Operationally, one example of placing the importance to the local natural environment of the campus is that USM has been able to register all the trees in its campus and locate them in an interactive map, which includes 27 different species. On a wider point, so as to raise the awareness of all actors about these efforts, various elements were accorded specific attention. This 
includes the existing philosophy of development, taking into consideration the prevailing natural beauty, such as the lakes and its surroundings, as well as the inhabitants, the interrelationship with design and architectural features, and also lifestyles of the campus community.

The example of the University in a Garden is particularly pertinent considering the fact that it has been recently suggested that the university campus's biophysical setting can be regarded as a place "where learning occurs” but which is, itself, "the source of no useful learning” (Savanick, String \& Manning, 2008, p. 668). However, through the process of assigning the campus's biophysical environment as a central, generative, reflexive, ambiguous space, The University in a Garden could centrally inform the built, virtual and social learning environment through trans-disciplinary research and teaching activities within such a counter-space. This argument recognizes other researchers, who emphasize the relevance of lived experience, for enhancing the transformative capacity of education for sustainability and note the importance of how the physical campus impacts on behavior (Hopkinson, Hughes \& Layer, 2008). It also concurs with Lozano, Lukman, Lozano, Huisingh \& Lambrechts, W. (2011) who argue for on-campus life experiences to be integrated systemically in universities participating in the sustainability transition.

Other potential counter-spacing initiatives (which again move beyond the incremental) currently being researched by the author, include how the local/regional community could act as generative, ambiguous counter-spaces. A pertinent example of such an initiative is the "Oberlin Project" set up by the Oberlin College, in the U.S.A. Redell (2010) describes the Oberlin Project as an arts district and regional economic and 
educational catalyst that would include a 20,000-acre working “greenbelt.” In an interview by Redell (2010 p. 2), Professor David Orr, the Paul Sears Distinguished Professor of Environmental Studies and Politics, the leading exponent of this initiative, talks about his excitement for The Oberlin Project functioning as a “learning lab” for many different areas of sustainable living and development, as well as eventually integrating with a larger network of national sustainability sites:

If we could see a town, in this case Oberlin, Ohio, as one giant school, we're going to learn collectively how we rejuvenate the economy, build great buildings, eat better food, rebuild the local ecological infrastructure around us, make it look good, work well, end poverty_ — at least take a big bite out of poverty ... How exciting could that be?

In an interview by Carlson (2011), Orr reflects on how he sees the university as embedded within a wider community counter-space and how this could challenge the extent of the university's purpose:

Why not get a holistic education in Oberlin, with people learning from teachers at the vocational school, the tradesmen with businesses here, the avid gardener, or the retired seamstress who lives down the street?

Similarly Orr reflects on the importance of extending the university school definition to the population of Oberlin, within the interview by Carlson (2011):

Imagine a curriculum here, where you take this whole city of 8,000 people and you do what the free universities were doing 30 years ago-learning from people 
here who know how to blacksmith, or make quilts, or can tomatoes. Imagine taking the whole population and making that the schoolhouse.

\section{Discussion}

By developing the conceptual notion of restorative heterotopic spacing for exploring potential bio-cultural pathways for academic actors, this paper has been able to move beyond the imperative of deepening attachments to the local settings (Johnson, 2012; Walck, 2003, 2004).

However, the notion that experiments with restorative counter-spaces, such as through the above local community and bio-physical campus strategic activities, could challenge the dominant performative university agenda, is not to be underestimated from personal experience. Although I am privileged to work in a riverside campus setting, I am keenly aware of the bio-cultural disconnection of the various academic actors of my university. Over the past seven years, I have always asked students their views on how the riverside setting affects their physical and emotional well-being and their working lives. To my chagrin, they invariably respond in puzzlement......”Which river? Where? What do you mean?” Clearly, the riverside setting, as part of a potential restorative counter-space has been secondary in favor of the grand sustainable, low carbon, built environment narrative, along with its blind adherence to its own rankings and metrics. The latter approach has further disengaged and disconnected many university actors towards the bio-physical environment, to the point where the notion of walking by the riverside and even venturing outside (apart from those organizational legitimized outside areas such as for smoking) is seen as such a non-instrumental, activity, that many academics, 
administrators and students alike do not attempt to escape over the physical, cultural and political walls. This is despite the implicit and complicit recognition of the psychological, ecological and bio-cultural restorative quality of such a pursuit. Focusing on this academic assimilation and allegiance, whenever I have suggested that we conduct a meeting a few paces outside the building, the general retort can be typified as follows...."I would like to do that, great idea, but I'm too busy for that, it would be nice if I wasn't so busy”. This paper's central tactical suggestion or proposition is that rather than abandoning the instrumental intent of many universities, they could break free of the bio-cultural constraints of such a pursuit by actively searching for multiple restorative, heterotopic spacing opportunities. This search could emerge not only externally but internally as well. Most crucially, this paper also moves beyond general spatial calls, such as to conduct meetings within the local bio-physical setting, by explicitly offering a conceptual frame to guide such counter-spacing. For example, following the principle of Fascination (from the proposed restorative framework), the significance of slowing down the cognitive and temporal would represent an aesthetic and temporal break from such meetings rather than a shift in setting. It is pertinent to note that such a focus on a biocultural aesthetic is a significant feature of both the University in a Garden and the Oberlin Project.

Furthermore, as campus culture and politics can play such a straight-jacketing role within such generative counter-spacing, what seems to be a significant feature of the proposed restorative framework, through the principle of Being-Away, is the significance of not only a psychological but a political and cultural distance from the dominant campus milieu. It is pertinent to note that, with respect to my personal vignette, there was an 
implicit assumption within many of the conference and whale watching participants, that such distanced activities are part of the whole experience of the conference for them. However, it must also be noted that these same academics are relatively senior within their respective universities, who thereby commanded a certain level of autonomy both within the conference and back at their institution. Moreover, without such autonomy, many university actors endeavoring to distance themselves through generative counterspacing, ironically require a higher degree of institutional support and strategic university leadership over time. It could be argued that initiatives such as the University in a Garden and the Oberlin Project offer such institutional support, as they are strategic in nature and are as much about reflecting upon the central purpose of the university, in contrast to many other micro campus initiatives, which are easily sidelined. This strategic perspective of course is also significant in terms of embodying the principle of Extent as both initiatives (high on coherence and scope) could have the ability to integrate the various generative counter-spacing opportunities and potentially foster a continuum of experience. However, this paper concurs with Beyes \& Michels (2011) who warn against such support being construed as organizing and planning such conceived "other spaces". Could the University in a Garden and the Oberlin Project become too centralized rather than embracing generative and emergent forms of counter-spacing? Alternatively, Rajchman (1998, p.104) calls for “operative formalism”, "where the issue is not what forms mean or represent, but what they do, what they can do". It is proposed here that such institutional support should be open to the possibility of misappropriation or detournement (Debord, 2004), of any conceived notion of what constitutes a restorative counter-space and embrace the socio-spatial enactment of generative space in new 
directions. As Sharma and Hart (2014) point out moving beyond curricular "greenwashing" requires a commitment by the Dean and the leadership of the School, along with support from key alumni and donors. This paper argues that such institutional support needs to offer not only the time and resources which Sharma and Hart (2014) highlight, but embrace the potential emotional and aesthetic counter-spacing opportunities for academics to open up new, surprising research ideas, to offer curricula innovations through emergent collaborations across disciplines.

This of course concurs with the Compatibility principle of the proposed framework. It is argued here that it represents a significant emergent factor which could be more fully taken into account in initiatives such as the University in a Garden and the Oberlin Project. In fact, with respect to the Oberlin Project, Carlson (2011) warns that observers say one of the project's main risks is that it could be perceived as an effete, academic endeavour. Carlson comments that many in the local community are already sceptical of the intellectuals' ideas in town. He argues that such intellectual leadership and strategic intent also requires a reflexive quality over time, as some local residents and officials have questioned whether academic ideals would sit well with the local community.

Such a generative, reflexive embrace is an implicit recognition that such restorative heterotopic spacing could ultimately engender a more creative and potentially more effective response to campus sustainability discourse. In other words, restorative counterspacing could equate to effective sustainability management. This was certainly the case for the personal vignette presented in this paper, around the way in which the original whale watching trip had reflexively changed a diverse set of disciplinary research 
agendas of multiple participants into a common trans-disciplinary engagement, around a sustainability discourse.

\section{Conclusions}

It is hoped that this paper's focus on restorative, heterotopic spacing could potentially offer a heuristic "pause”, cognitively and performatively, for university actors to more centrally invent "new slogans”, “experiments” and "maps” which are more fully "attuned to affect, sensation and atmosphere” around bio-cultural restoration (Beyes and Steyaert, 2012). Reflecting upon one such generative pause, emerging from an academic actor on campus, is the example of Brian Treanor, a philosophy professor, who in the summer of 2007, developed the idea of developing a "Slow University Manifesto" movement at Loyola Marymount University Campus in the U.S.A. Treanor (2007) invited other faculty members, students, staff, and administrators to join him—-to slow down. He began the experiment by establishing, posting, and maintaining explicit "slow hours" in his academic schedule, a practice he has continued to the present day. During these times he does not, under any circumstances, work. He does not read or write with the intent of developing a publication or conference paper. He does not prepare for class or grade papers. He does not attend any committee meetings. He does not answer the phone or respond to email. He does not do chores or run errands. In fact, he tries to avoid anything that smacks of being productive.

In his own words, he reflects not only temporally but most crucially for this paper, spatially, 
My slow hours are spent letting my thoughts wander, walking along the bluff, or talking and eating with family, friends, colleagues, and students. This is not out of a desire to be an idler per se, but out of recognition that at a certain point the more I do the worse I become: worse as a scholar; worse as a teacher; worse as a colleague; worse as a husband, father, friend. I believe that these slow hours actually result in better contributions here at LMU: better publications; better relationships with students; and better relationships with my colleagues.

It is hoped that this paper, at the very least, opens up a discourse and sensibility around identifying our own personal day-to-day micro restorative counter-spacing opportunities. No doubt, such a conversation will be as diverse as the examples provided here. This conversation cannot be divorced from the complexity of the interrelated political, cultural, internal, external, formal, informal, micro and macro institutional context and pressures of academia and sustainability. Such spatial thinking allows for such ambiguity and contradictions, in contrast to purely thinking within a temporal horizon which is inextricably linked to a linear unfolding of events in time (Kornberger and Clegg, 2004). Reflecting upon Treanor's quote above, this publication could certainly not have been written without an acute day-to-day appreciation of the importance of finding suitable restorative, heterotopic spacing opportunities to counter the author's fast, performative, academic life. It is this paper's contention that whilst time provided for such spacing opportunities through sabbaticals, blocked off teaching and such "slow hours" is significant, the ART/heterotopic spacing framework proposed here offers a conceptual signposting for such a generative, contextual search. 


\section{References}

Bateson, G. (1967). Consciousness versus Nature. Peace News, 1622 (July 28), 10.

Berry, W. (1972). Think Little: a Continuous Harmony: Essays Cultural and Agricultural.Shoemaker and Hoard, Washington, D.C

Beyes, T. \& Michels, C. (2011). The production of educational space: Heterotopia and the business university. Management Learning, 42 (5), 521-536.

Beyes, T., Steyaert, C. (2012) Spacing organization, non-representational theory and performing organizational space. Organization, 19(1), 45-61.

Canter, D.V. (1977). The Psychology of Place. London: Architectural Press.

Carlson, S. (2011). Oberlin, Ohio: Laboratory for a New Way of Life. The Chronicle of Higher Education. November 6, 2011.

Collins, D. \& Gannon, A. (2014). Walking the Eco-Talk Movement: Higher Education Institutions as Sustainability Incubators. Organization \& Environment, 27 (1), 16-24. Collinson, D. (1992). Aesthetic experience. In O. Hanfling (ed), Philosophical Aesthetics: An Introduction (pp. 111-78). Milton Keynes: The Open University. Cortese, A.D. (2003). The critical role of higher education in creating a sustainable future. Planning for Higher Education, 31(3), 15-22.

Cranton, P., \& Roy, M. (2003). When the bottom falls out of the bucket: Toward a holistic perspective on transformative learning. Journal of Transformative Education, 1(2), 86-98.

De Certeau, M. (1984). The Practice of Everyday Life. Berkeley, Los Angeles: University of California Press. 
Debord, G (2004). The Situationists and the new forms of action in politics or art. In: McDonough, T (ed.) Guy Debord and the Situationist International: Texts and Documents. Cambridge, MA: MIT Press, 159-166.

Dewey, J. (1938). Experience and Education. New York: Collier Books.

Dey, P., Steyaert, C. (2007). The Troubadours of Knowledge: Passion and Invention in Management Education. Organization, 3, 437-461.

Disterheft, A., Ferreira da Silva Caeiro, S.S., Ramos, M.R., Manuel de Miranda Azeiteiro, U. (2012). Environmental Management Systems (EMS) implementation processes and practices in European higher education institutions - top down versus participatory approaches. Journal of Cleaner Production, 31, 8-90.

Duerr, M., Zajonc, A., \& Dana, D. (2003). Survey of transformative and spiritual dimensions of higher education. Journal of Transformative Learning, 1(3), 177-211. Flyvbjerg, B. (2001). Making Social Science Matter: Why Social Inquiry Fails and How It Can Succeed Again. Cambridge: Cambridge University Press.

Foucault, M (1984). The Care of the Self: The History of Sexuality Vol. III (R Hurley, Trans.). New York: Pantheon.

Foucault, M. (1997). Ethics Subjectivity and Truth (The Essential Works of Michel Foucault 1954-1984 Vol. 1) (R Hurley, Trans.). P. Rabinow (Ed.). New York NY: New Press.

Gagliardi, P. (1996). Exploring the aesthetic side of organizational life. In: S. Clegg, C. Hardy \& W. Nord (Eds.), Handbook of Organizational Studies (pp. 565-580). London: SAGE. 
Gagliardi, P. (1999). Exploring the aesthetic side of organisational life. In S. Clegg \& C. Hardy (Eds.), Studying Organisation, Theory and Method. London: SAGE.

Gherardi, S. (1999). Learning as Problem-driven or Learning in the Face of Mystery? Organization Studies, 20(1), 101-24.

Gould, K. A. (2000). Sustainability across borders: Transnational ecotourism, globalization and place in Western Belize'. Paper presented at the International Sociological Association RC24 Miniconference, Rio de Janeiro, 1-3 August.

Guthey, G. T., \& Whiteman, G. (2009). Social and ecological transitions: Winemaking in California. Emergence: Complexity \& Organization, 11, 37-48.

Hall, E. T. (1959). The silent language. New York: Doubleday. Hancock, P. (2003). Aestheticizing the World of Organization: Creating beautiful untrue things. In A. Carr \& P. Hancock (Eds.), Art and Aesthetics at Work (pp. 174 - 194). London: Palgrave Macmillan.

Hartig T, Kaiser F.G. \& Strumse, E. (2007). Psychological restoration in nature as a source of motivation for ecological behaviour. Environmental Conservation, 34, 291299.

Hartig, T. (2007). Three steps to understanding restorative environments as health resources In C. Ward Thompson \& P. Travlou (Eds.), Open space, people space (pp. 163-179). London: Taylor and Francis.

Hartig, T., Bringslimark, T. \& Gridal Patil, G. (2008). Restorative Environmental Design: What when where and for whom? In S. Kellert, J.H.Heerwagon \& M.L. Mador (Eds.), Biophilic Design. New Jersey: John Wiley and Sons. 
Herzog, T. R. Black,M. A., Fountaine, K.A. \& Knotts, D. J. (1997). Reflection and attention recovery as distinctive benefits of restorative environments. Journal of Environmental Psychology, 17, 165-170.

Herzog. T.R., Maguire, C.P., Nebel M.B. (2003). Assessing the restorative components of environments. J. Environ. Psychol., 23, 159-170.

Hopkinson, P., Hughes, P. \& Layer, G. (2008). Sustainable graduates: linking formal, informal and campus curricula to embed education for sustainable development in the student learning experience. Environmental Education Research, 14(4), 435-454. Huisingh, G., Mebratu, D. (2000). “Educating the educators” as a strategy for enhancing education on cleaner production. Journal of Cleaner Production, 8, 439-442.

John, E. (2001). Art and knowledge. In B. Gaut \& D. Lopes (Eds.). The Routledge Companion to Aesthetics (pp. 329-52). London: Routledge.

Johnson, V. (2012), Identity, Sustainability, and Local Setting at U.S. Botanical Gardens. Organization Environment, 25 (3), 259-285.

Jones, D.R. (2012). Looking through the 'Greenwashing Glass Cage’ of the Green League Table towards the Sustainability Challenge for UK Universities. Journal of Organizational Change Management, 25(4), 630 - 647.

Kals, E, Schumacher, D. \& Montada, L. (1999). Emotional affinity toward nature as a motivational basis to protect nature. Environment and Behavior, 31(2), 178-202. Kaplan, R. \& Kaplan, S. (1989). The experience of nature: A psychological perspective. Cambridge UK: Cambridge University Press.

Kaplan, R. (2001). The nature of the view from home: Psychological benefits. Environment and Behavior, 33, 507-542. 
Kaplan, S.(1995). The restorative benefits of nature: Toward an integrative framework. Journal of Environmental Psychology, 15, 169-182.

Kaplan, S., Bardwell, L.V. \& Slakter, D.A. (1993). The museum as a restorative experience. Environment and Behavior, 25, 725-742.

Kearins, K., Collins, E. \& Tregidga, H.( 2010). Beyond corporate environmental management to a consideration of nature in visionary small enterprise. Business and Society, 49(3), 512-47.

Kellert, S.R. (2008). Dimensions Elements and Attributes of Biophilic Design. In S. Kellert, J.H.Heerwagon \& M.L. Mador (Eds.), Biophilic Design. New Jersey: John Wiley and Sons.

Keulartz, J. (2007). Using metaphors in restoring nature. Nature and Culture, 2, 27-48. Kornberger, M. \& Clegg, S.R. (2004). Bringing Space Back In: Organizing the Generative Building. Organization Studies, 25(7), 1095-114.

Korpela, K. \& Hartig, T. (1996). Restorative qualities of favorite places. Journal of Environmental Psychology, 16, 221-233.

Korpela, K.M., Hartig, T., Kaiser, F.G. \& Fuhrer, U. (2001). Restorative Experience and Self-Regulation in Favorite Places. Environment and Behavior, 33, 572-589.

Krinke, R. (2005). Landscapes of Contemplation. London: Routledge.

Kuo, F.E. \& Sullivan, W.C. (2001). Aggression and violence in the inner city: Effects of environment via mental fatigue. Environment and Behavior, 4, 543-571.

Kuo, F.E. (2001). Coping with Poverty- Impacts of Environment and Attention in the Inner City. Environment and Behavior, 33(1), 5-34. 
Leach, M. (1998). Culture and Sustainability. In L. Emmerji \& P. Streeton (Eds.), World Culture Report (pp. 93-104). Paris: United Nations Educational Scientific and Cultural Organization.

Lefebvre, H. (1991). The production of space. Oxford: Blackwell.

Lozano, R., Lukman, R., Lozano, F.J., Huisingh, D. \& Lambrechts, W. (2011).

Declarations for sustainability in higher education: becoming better leaders, through addressing the university system. Journal of Cleaner Production,

DOI:10.1016/j.jclepro.2011.10.006

Lozano, R., Lukman, R., Lozano, F.J., Huisingh, D., Zilahy, G. (2010). Jumping

Sustainability Meme. SD Transfer from Society to Universities. Paper presented at the Environmental Management for Sustainable Universities. Delft, the Netherlands. Macnaughten, P., \& Urry, J. (1998). Contested natures. London: Sage.

McIntosh, A.(2004). Soil and Soul: People versus Corporate Power. London: Aurum. Mochizuki, Y. \& Fadeeva, Z. (2008). Regional centres of expertise on education for sustainable development (RCEs): an Overview. International Journal of Sustainability in Higher Education, 9 (4), 371-379.

Morgan, G. (2011). Reflections on Images of Organization and its implications for studies of organization and environment. Organization \& Environment, 24, 459-478. Ouellette, P., Kaplan, R. \& Kaplan, S. (2005). The monastery as a restorative environment. Journal of Environmental Psychology, 25(2), 175-188.

Philippon, D. J. (2004). Conserving words: How American nature writers shaped the environmental movement. Athens: University of Georgia Press. 
Polanyi, M. (1958, reprinted in 1978). Personal Knowledge: Towards a Post-Critical Philosophy. London: Routledge and Kegan Paul.

Purcell, T., Peron, E. \& Berto, R. (2001). Why do preferences differ between scene types? Environment and Behavior, 33(1), 93-106.

Rajchman, J (1998). Constructions. Cambridge, MA: MIT Press.

Reddell, C. (2010). New Era for David Orr. Sustainable Industries Magazine. March2010.

Rudofsky, B. (1964). Architecture without Architects: a Short Introduction to Nonpedigreed Architecture. London: Academy Editions.

Ryan, M. (2011). Productions of space: civic participation of young people at university. British Educational Research Journal, 37(6), 1015-1031.

Sanusi ZA, Khelgat-Doost H (2008). Regional centre of expertise as a transformational platform for sustainability: a case study of Universiti Sains Malaysia, Penang. International Journal of Sustainability in Higher Education, 9, 487-497

Savanick, S., String, R. \& Manning, C. (2008). Explicitly linking pedagogy and facilities to campus sustainability: lessons from Carleton College and the University of Minnesota. Environmental Education Research, 14 (6), 667-679.

Sharma, S. \& Hart, S. (2014). Beyond “Saddle Bag” Sustainability for Business Education. Organization \& Environment, 27(1), 10-15.

Shrivastava, P \& Kennelly, J.J. (2013). Sustainability and Place-Based Enterprise. Organization \& Environment, 26(1), 83-101.

Shusterman, R. (2001). Pragmatism: Dewey. In B. Gaut \& D. Lopes (Eds.), The Routledge Companion to Aesthetics (pp. 97-106). London: Routledge. 
Sloterdijk, P. (2010). Scheintod im Denken: Von Philosophie und Wissenschaft als Übung. Frankfurt am Main: Suhrkamp.

Soja, E. W. (1996).Thirdspace. Malden (Mass.): Blackwell.

Starik, M. \& Turcotte,M-F. (2014). With a Little (Urgent) Help From Our Friends: Management Academic Leadership for a Sustainable Future. Organization \& Environment, 27(1), 3-9.

Steyaert, C. (2006). Cities as Heterotopias and Third Spaces: the Example of ImagiNation the Swiss Expo 02. In S. Clegg \& M. Kornberger (Eds.), Space Organizations and Management Theory (pp. 248-265). Copenhagen: Liber and Copenhagen Business School Press.

Stibbe, A. (2009) The Handbook of Sustainability Literacy: Skills for a Changing World. Dartington: Green Books.

Taylor, S. \& Spicer, A. (2007). Time for Space: An Interpretive Review of Research on Organizational Spaces. International Journal of Management Reviews, 9(4), 325-346. Taylor, S. S., Hansen, H. (2005). Finding form, looking at the field of organizational aesthetics. Journal of Management Studies. 42 (6), 1211-32.

Thomas, D. F., \& Cross, J. E. (2007). Organizations as place builders. Journal of Behavioral and Applied Management, 9(1), 33-61.

Treanor, B. (2007). Slow University, A manifesto. Retrieved from http://myweb.lmu.edu/btreanor/Slow University Manifesto.htm (17 October, 2010) Tuan, Y-F. (1977). Space and Place: The Perspective of Experience 1977. Minneapolis MN: University of Minnesota Press. 
Ulrich, R. S. (1993). Biophilia, biophobia, and natural landscapes. In S. R. Kellert \& E. O. Wilson (Eds.), The biophilia hypothesis (pp.73-137). Washington, DC: Island Press. Ulrich, R.S. \& Parsons, R. (1992). Influences of passive experiences with plants on individual well-being and health. In D. Relf (Ed.), The role of horticulture in human wellbeing and social development (pp.93-105). Portland OR: Timber Press.

USM (2012). University in a Garden, available at:

http://www.usm.my/index.php/en/about-usm/making-adifference/the-university-in-agarden.html (accessed 26.09.13).

Walck, C. (2003). Using the concept of land to ground the teaching of management and the natural environment. Journal of Management Education, 27, 205-219.

Walck, C. (2004). Healing the divided mind: Land as an integrating concept for organizations and the natural environment. Organization \& Environment, 17, 170-194. Wells, N.M. \& Evans, G.W. (2003). Nearby Nature: A Buffer of Life Stress Among Rural Children. Environment and Behavior, 35(3), 311-330.

Welsch, W. (1997). Undoing Aesthetics (A Inkpin, Trans.). London: SAGE.

Whiteman, G.M. \& Cooper, W.H. (2000). Ecological Embeddedness. Academy of Management Journal, 43(6), 1265-1282.

Whiteman, G.M. \& Cooper, W.H. (2006). Sixty six ways to get it wrong: A response to Banerjee \& Linstead. Human Relations, 59(3), 409-428.

Whiteman, G.M. (2004). Why are we talking inside? Reflecting on traditional ecological knowledge (TEK) and management research. Journal of Management Inquiry, 13(3), 261-277. 